Gómez Cremades, Ana María.

Profesora, Universidad de Granada, Departamento de Dibujo.

Miembro del grupo de investigación HUM-184, Universidad de Sevilla. Departamento de Escultura.

\title{
Síntesis, dibujo y forma de los "teatros personales" de Cezary Bodzianowsky: el gag visual como estrategia del discurso contemporáneo
}

\section{Synthesis, drawing and form in Cezary Bodzianowsky's "personal theaters": the visual gag as a strategy in contemporary discourses}

TIPO DE TRABAJO: comunicación.

PALABRAS CLAVE

Arte contemporáneo, artes visuales, gag, performance, cultura objetual.

KEY WORDS

Contemporary art, visual art, gag, performance, object culture.

RESUMEN

Indiscreta y avasallada por las nuevas tecnologías, además de brindar riqueza visual y multiculturalidad, la imagen controvierte y excede el imaginario colectivo. El problema, explica Fontcuberta en La cámara de Pandora (2010), es que "de tanto ver, ya no vemos nada: el exceso de visión, conduce a la ceguera por saturación». La desproporción visual puede efectivamente enturbiar la visibilidad y el entorno, pero lo más relevante y significativo es la manera en cómo la gestionamos.

En el convencimiento de que en el contexto actual hace falta más sentido del humor y risas, este artículo nos acerca a la sátira del escenario cotidiano a través del arte. Así, tomando como punto de partida una de las figuras que más representa, dice y desdice del factor humano, el payaso -concretamente el payaso del cine primitivo-, nos proponemos trazar los probables y posibles de lo que parece convertirse en una nueva estrategia discursiva: el gag visual.

Entre la payasada y el silencio de sus pantomimas, los teatros personales del artista polaco Cezary Bodzianowsky nos inducen a reflexionar lo acostumbrado. Consciente de que el imaginario popular mueve y conmueve, concluye, burla y perturba el circo contextual contemporáneo, la travesura visual de Bodzianowsky nos invita a parar, a detener el tiempo y los sentidos. Mientras el exceso nos excede y abruma, en el análisis de su obra descubrimos la síntesis performativa y descaro de un personaje universal que devora el desatino cotidiano.

Ante el desarraigo y cultura objetual contemporánea, Bodzianowsky gestiona la absurdidad del comportamiento social. Hábil estratega de todas esas relaciones humanas y materiales que la obra burlesca utiliza como moneda de cambio, lo concreto y la pausa más que el exceso y la prisa, nos invitan en su discurso a especular el entorno de manera menos seria, pero más comprometida.

\section{ABSTRACT}

Overwhelmed by new technologies, allowing visual richness and multiculturalism, contemporary imaginary exceeds the collective perception and imagination. The problem -explains Fontcuberta in Pandora's Camera (2010)- is that vision saturation causes us to no longer see. Saturation instigates blindness. Even though image disproportion can effectively cloud our visibility and environment, the fundamental lies in the way we manage it. 
Convinced that in the current context it is needed more sense of humor and laughter, this article brings us closer to the everyday farce through art. Thus, taking as a starting point one of the figures that better represents, explains and contradicts the human factor, i.e. the clown, specifically the primitive slapstick clown, we propose to trace the probabilities and possibilities of what seems to become a new discursive strategy: the visual gag.

Beyond the buffoonery and the silence of his pantomimes, the "personal theaters" of the Polish artist Cezary Bodzianowsky reflect on the ordinary. Aware that the popular imaginary moves, teases and disturbs the contemporary contextual circus, Bodzianowsky visual interferences instigate to stop, to freeze time, space and all senses. While the excess exceeds and overwhelms us, in the analysis of his artwork we discover the synthesis and audacious performativity of a universal character that devours the daily folly.

Aware of the uprooting and contemporary object culture, Bodzianowsky manages the absurdity of social behavior. He turns to be a skillful strategist of the human and material relationships that humor exchanges. So that, by choosing the specific and the pause rather than the excess and the haste, his artwork seduces and speculates the context in a more enthusiastic way.

\section{INTRODUCCIÓN: PERSONAJES, METODOLOGÍA Y CONTEXTO}

En su artículo /l cinema nasce dal circo, Verdone equipara la entrada clownesca del número de circo con la comedia cinematográfica primitiva, determinando en ambos casos los siguientes denominadores comunes: brevedad, un protagonista clown-acróbata, el ingrediente slap-stick (los golpes y caídas), y el gag (Arpa, Chiti, Pantieri, Popeschich, Verdone, \& Zocaro, 1992, pp. 89-102). Estos mismos ingredientes conforman, complementan y contradicen con frecuencia el imaginario del artista contemporáneo burlesco y el desconcierto contextual.

Es el motivo por el que esta comunicación indaga en la estrategia clownesca para confrontar el entorno. ¿El contexto? El cine primitivo y el discurso contemporáneo. ¿Los protagonistas? El payaso silente del pasado y el artista visual de nuestro tiempo. ¿El método? El análisis documental. ¿El modelo? La trayectoria y obra del artista polaco Cezary Bodianowski. ¿Los contenidos? Fiel a su desarrollo en el tiempo y la historia, este escrito se centra primero en el payaso, lo clownesco y el gag visual como fórmula; y luego revisita las propuestas de un artista que se burla de sí mismo y el otro para reflexionar el entorno.

\section{DESARROLLO}

Conquistada por las nuevas tecnologías, además de enriquecer lo visual y la multiculturalidad, la imagen controvierte y excede el imaginario colectivo. El problema, explica Fontcuberta (2010), es que «de tanto ver, ya no vemos nada: el exceso de visión, conduce a la ceguera por saturación». La desproporción visual puede enturbiar el entorno, pero también puede incitarnos a repensarlo de manera menos prejuiciosa y más flexible. El artista contemporáneo lo tiene claro. La táctica es dejar de tomarse todo tan en serio. Y el payaso le da la clave.

\section{El payaso primitivo y el pie de entrada clownesco}

Partiendo de la ecuación de equivalencia que proponía el escritor y pintor italiano Ardegno Soffici, "clown = artista puro», Aldo Palazzeschi escribe en 1913 que el payaso, «representa mejor que ninguna otra figura al artista desinteresado; la idea del divertimento por el divertimento» (cit. por Vittori, 1990, p. 41). Leydi y Bragaglia por su parte, argumentan que "el payaso ha aprendido a hacer la caricatura de la vida en bocetos breves, pero se supera y sublima cuando hace la caricatura de sí mismo» (1959, p. 199). Esa figura desinteresada del payaso y sus caricaturas de la vida... motivan este primer apartado.

Centrándose en el gag, Noël Carroll (1991) nos describe «el debacle cómico» como accidentes expandidos, reinados libres y sadismos compartidos. A finales del XIX y principios XX, surge un medio particularmente afín a dichos debacles y accidentes monumentales que giran en torno a la pantomima del gesto, la negación de la palabra y la imagen monocroma en blanco y negro. La gramática del lenguaje cinematográfico aún ni existía, todo era juego y experimentación. Entre patadas, carreras imposibles y caídas libres, el payaso y la performance clownesca -los Keystone Kops del cine de Mack Sennett ${ }^{1}$ lo demuestran-, renegocian la tecnología con el factor humano.

\footnotetext{
1 Mack Sennett (1860-1980). Pionero y sistematizador del medio en los orígenes y desarrollo de la industria cinematográfica hollywoodiense. El primer cineasta y productor en defender la comedia cinematográfico como género propio. Los Keystone kops hacen referencia a esos policías incompetentes y destartalados que siempre van a las carreras, y que jamás consiguen resolver sus urgencias. $\mathrm{Y}$ si lo hacen, es solo por pura coincidencia.
} 
Paraíso de lo concreto, la crueldad y la desmesura de la experiencia física, el circo proporciona a la comedia cinemática un personaje que deviene coautor de la exageración, de la incoherencia, de la (in)exactitud de la intención y el movimiento. Entre acróbatas, músicos y payasadas, lo inevitable es el pie de entrada del cómico. A tal efecto, Piercarlo sistematiza (1) el pie de entrada repentino (o relámpago) donde se impone la inmediatez y la sorpresa del gesto; (2) el extendido, en el que tiene cabida un monólogo, un trabalenguas o todo tipo de juegos de palabras y pantomimas; (3) los planos superpuestos o compuestos cuya fórmula, comportándose como un legítimo collage en movimiento, se explica en varias secuencias; y (4) el doble, donde una especie de campocontra-campo de agudas réplicas se ejercitan por lo general en pareja (1979, pp. 19-20). El pie de entrada es lo que motiva el resto, lo que sugiere la acción, la relación entre objetos, intenciones y personajes. En la similitud de escenarios pretéritos y contemporáneos, el artista contemporáneo recurre con frecuencia a tácticas similares parpara confrontar el contexto.

\section{El gag visual: síntesis, acción y destreza}

Aislado, el gag es un mecanismo indefinible que sirve para hacer reír [...] Nadie ha podido rescatar con palabras la parte sensible del gag, visual o verbal, que es lo que lo vuelve eficaz. Cuando se procura edificar una definición [...] se obtienen resultados tan complicados que la esencia del gag, muy simple, deja de existir (Martín Peña, 1991, p. 18).

Ya sea como «incidente brutal», o como esa «elipse visual» que plantea Piercarlo citando a Roger Regente (1979, p. 12), la comedia slapstick ${ }^{2}$ en palabras de François Mars, la concreta el impulso propio de sus gags. Lo que se reduce a la fórmula «Film = Gag» (Mars, 1964, p. 21). Y, si como asegura Alan Dale, «la esencia del gag slapstick es un asalto físico "a" o el colapso "de" la dignidad del héroe» $(2000$, p. 3), la consecución de asaltos físicos y colapsos - no solo a y de la dignidad-, sino a y de la perversión de los sentidos y la lógica, serán los que fundamenten la imagen silente y el despropósito del imaginario burlesco contemporáneo.

El número cómico puede subsistir sin los giros del argumento, o la solidez del personaje, pero no puede hacerlo sin la desproporción y la absurdidad del gag. Haciendo uso de la técnica y el trucaje, la evolución y revolución de la lógica tradicional y el (des)propósito del factor humano, convierte el gag en el prototipo predilecto, no solo del lenguaje primitivo slapstick sino también del discurso contemporáneo. El gag, asegura Mars, parte ante todo de una necesidad intelectual, algo así «como la admiración que se experimenta al ver una obra de arte que se aprecia juiciosamente, pero que no se sabría crear» (1964, p. 82). La rendición absoluta ante la adversidad y el equívoco, la no-lógica o la lógica puesta del revés, y esa obligatoriedad experimental amparan el ingenio del gag visual como estrategia.

Testigo y cómplice de una situación que arroja angustia y desconsuelo, alivio y risa al mismo tiempo, el gag se convierte en un arma de doble filo. Entre objetos, eventos y muchos ojos que lo miran, el cómico gestiona sus gags de mil maneras. Para sistematizar el uso de la forma (objeto) y la performance (eventualidad) cómica, tomamos como referencia la categorización que establece Nöel Carroll (1991, pp. 28-38) en torno al gag y su confrontación con el evento, el objeto, el personaje y el espectador. Seis son sus posibles maniobras:

1. Interferencia mutua. Se produce entre dos (o más) series de eventos o escenarios. En ella, el personaje confunde lo que cree que está pasando con lo que ocurre en realidad, y el público es testigo de su error y confusión.

2. Metáfora mímica. Pantomima que atiende aspectos más objetuales que situacionales en sus alegorías.

3. Imagen cambiante. Conflicto de imágenes que se muestra de manera secuencial. Es decir, se ordena como la narrativa de un chiste y no suele recurrir a la metáfora mímica. Es, en definitiva, más eventual que objetual.

4. Movimiento cambiante. Una especie de chiste visual envuelto en un juego secuencial de interpretaciones y reinterpretaciones múltiples que se prestan a la confusión y lo inestable.

5. Objeto análogo. Más en la línea de la metáfora mímica pero sin pantomima, lo que hace es negociar y mostrar de forma simultánea el objeto real y su metáfora.

6. Solución. Se comporta como un juego alternativo de interpretaciones secuenciales. Pero esta vez, en lugar de ser el personaje el que tiene una visión parcial de lo que está ocurriendo (como ocurre en la interferencia), es el público el que ignora, total o parcialmente, la eventualidad.

En cualquiera de los casos, la reversión del concepto y la lógica tradicional, la síntesis, acciones y destrezas del gag como discurso se concluye a sí mismo como un momento sorpresivo y contrario de la escena, que se desarrolla acorde a la siguiente fórmula:

2 En referencia a la primitiva comedia muda perteneciente a una época donde el cine, fundamentalmente, es espectáculo visual y movimiento. 
En la excentricidad de su clímax final, y la tensión que mantiene intentando conquistar la carrera justo en la última vuelta, Donald Crafton describe el gag como «los baches, desvíos y ruedas pinchadas que la efervescente lata de la narración, encuentra en su camino hacia el final de la película» (Bowser, 1988, p. 54). En la precipitación de su descenso, entre curva y curva, bache y bache, ruedas pinchadas y parches, el discurso contemporáneo se reinventa. En palabras de Kràl, «la exactitud misma del gag, tanto de su idea como de su ejecución, estaba ahí sólo para sugestionar en el mundo una tormenta de libertad» (2007, p. 300). En su exceso cómplice, contrario y caprichoso, esa tormenta de libertad es la que posiciona el gag como táctica incondicional de lo contemporáneo. La obra y discurso de Cezary Bodianowski lo demuestran.

\section{Cezary Bodzianowski: el desatino cotidiano vs. el teatro personal de los eventos}

Considerando sus performances "un teatro personal de los eventos", el trabajo de Bodzianowski tiene mucho en común con la tradición dadaísta y, aunque privado de su desafío moral y tendencia al escándalo, evoca el carácter del grupo Łódź Kaliska³. Contrario a este, él está interesado en los comportamientos y actitudes sociales - tales como tolerancia, apertura, espontaneidad-, las cuales explora a través de sus acciones (Gorządek, 2015).

Fiel al idiotismo contemporáneo y su falta de instrucción, la fascinación que representa el payaso y acróbata, en palabras de Vittori, "deriva de su capacidad para intuir un espacio sin reglas, quizá excéntrico, desordenado, pero capaz de restaurar al mundo la autenticidad perdida en unos valores rígidamente codificados», de esta forma, su estupidez se convierte en algo "providencial ya que desenmascara lo falso, lo inauténtico» (1990, p. 27). En este mismo sentido, desenmascarando la absurdidad del entorno y transformando la banalidad en algo extraordinario, el disparatador slapstick contemporáneo se convierte en acróbata y malabarista del desatino cotidiano. Renegociando sus acciones y esperas con la escultura, la performance, la fotografía y el video, la integridad del gesto de Cezary Bodzianowski escenifica la sublevación de la incoherencia objetual y performativa del imaginario colectivo.

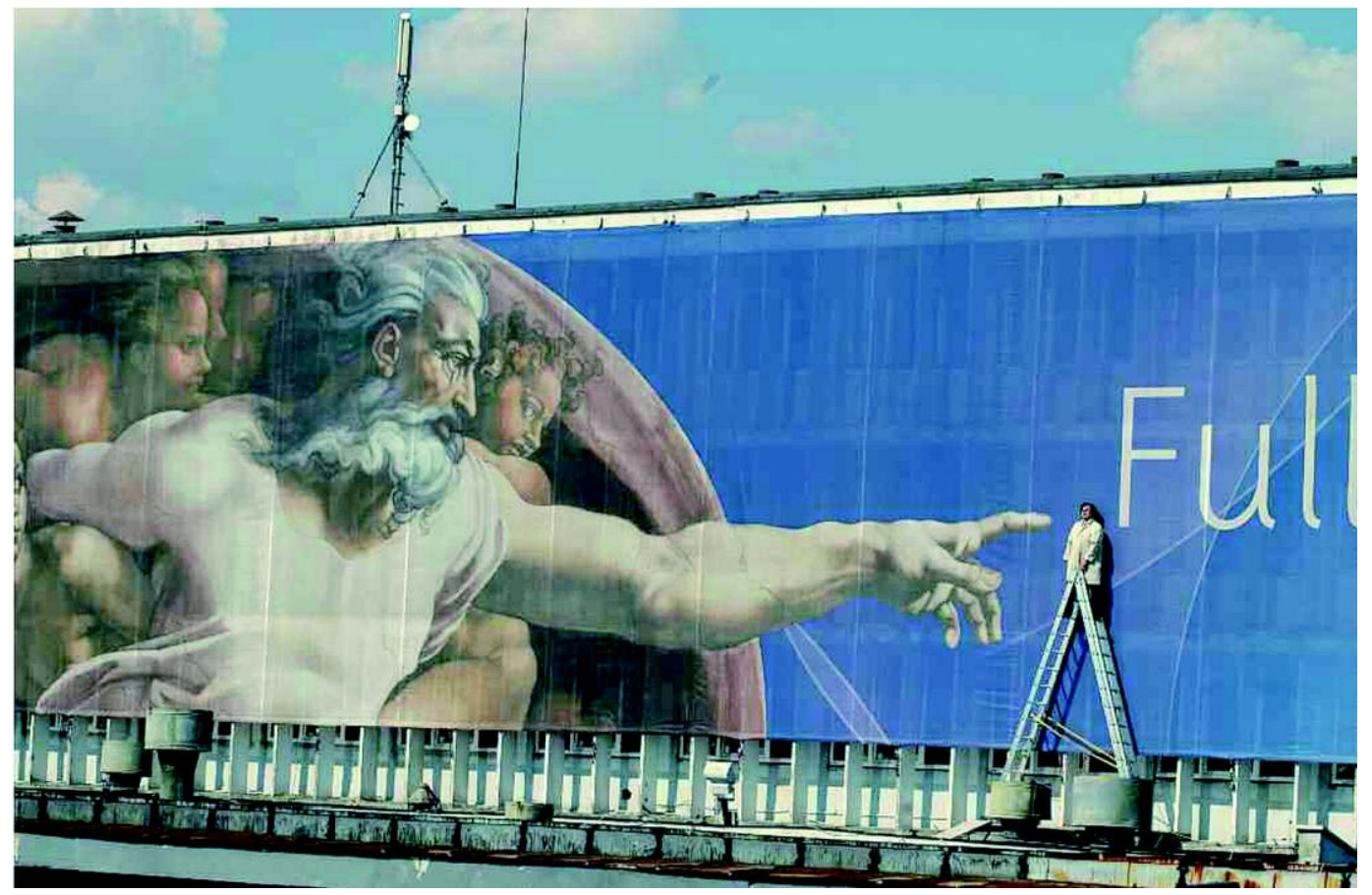

Figura 1. Cezary Bodzianowski. Onto, 2009

\footnotetext{
3 El grupo artístico neovanguardista Łódź Kaliska conformado por Marek Janiak, Andrzej Kwietniewski, Adam Rzepecki, Andrzej Świetlik y Andrzej Wielogórski, se creó en 1979 y desde sus orígenes su práctica estuvo ligada a la provocación y al escándalo (premeditado). Críticos de la religión y el patriotismo, su humorismo analiza la historia de la cultura como «almacén de formas», donde desaparece, se diluye u olvida la división entre lo sagrado y profano (véase Propaganda, s.f.)
} 
En su libro Gag: guida alla comicità slapstick, Angelo Moscariello categoriza las tipologías del gag como realista, surrealista y parodista. Luego, estipula sus formas, veinticinco en total (véase Moscariello, 2009, pp. 39-88). Entre ellas, incluye las más recurridas en la mundología de Bodianowski. Es decir, la figura en el paisaje, la repetición, la inversión, el equívoco, la interferencia o la incongruencia. El intercambio o la rebelión del objeto, son igualmente tácticas infalibles en su imaginario. La fórmula escénica del gag se evidencia en cada una de sus propuestas. ¿Y cual es la estrategia? Tres tempos la determinan. Esto es, «la preparación, la espera, y la ruptura cómica» (Celati cit. por Cremonini, 1977, p. 20).

Mientras se acomoda y espera, el artista polaco se muestra impasible, invisible, negado. "Su apariencia resulta positivamente impenetrable. Ningún tribunal en el mundo podría impugnar la motivación que empuja las acciones de este hombre. No hay manera de determinar qué es lo que le conmueve» (Verwoert, 2007). Sin mediar la más mínima palabra, la boca siempre cerrada, y la mirada imprecisa y atenta, «el único rastro de burla que se podría discernir en sus representaciones es el bigotito que, como si fuese parte de sí mismo, Bodzianowski ha llevado desde sus primeras performances» (p. 241). Su extralimitación, es la del gesto pausado en medio del exceso habituado. Sin gesticular una sola mueca, nunca particularmente feliz ni triste, ni enojado, ni tampoco necesariamente lo contrario, se convierte en una especie de mimo del no gesto. Sus escenarios, objetos y personajes se preparan, esperan y rompen el desatino cotidiano.

Como para todo buen payaso, la mascarada contemporánea se torna motivo de risa y teatro del absurdo. Así, copartícipe y desafiante de la desmesura, su obra reinventa el imaginario contextual. Su "solidaridad existencial» nos permite percibir, en palabras de Verwoert, que «Bodzianowski el artista es también Bodzianowski el ciudadano universal» (2007, p. 242). Se trata de un «personaje cualsea» (Agamben, 1996). Improvisando el absurdismo cotidiano y la comunidad que lo acecha, Bodzianowski deviene «impropiedad» ${ }^{4}$ clownesca, síntesis, y dibujo escénico. Grafías que, como el gag visual, saturan los sentidos con sus interferencias, metáforas, imágenes cambiantes y analogías.

En la contemplativa actitud de un individuo solitario que desafía el vértigo que provoca el levantarse por la mañana un día cualquiera, en Serenade (2006), sentado al borde de un precipicio, Bodzianowski siente -de sentir, y también quizá de arrepentirse- que la cima del mundo le pertenece tanto como se le escapa de las manos. Sitiado en el extremo de una azotea, al igual que Van der Werve estático y meditativo en el Polo Norte, William Pope.L gateando las calles de Nueva York, Burden disparando aviones en las playas de California o Bas Jan Ader subido al tejado de una casa, el personaje clownesco y cualsea que representa Bodzianowski se prepara y anula en el ruido y desacierto del entorno.

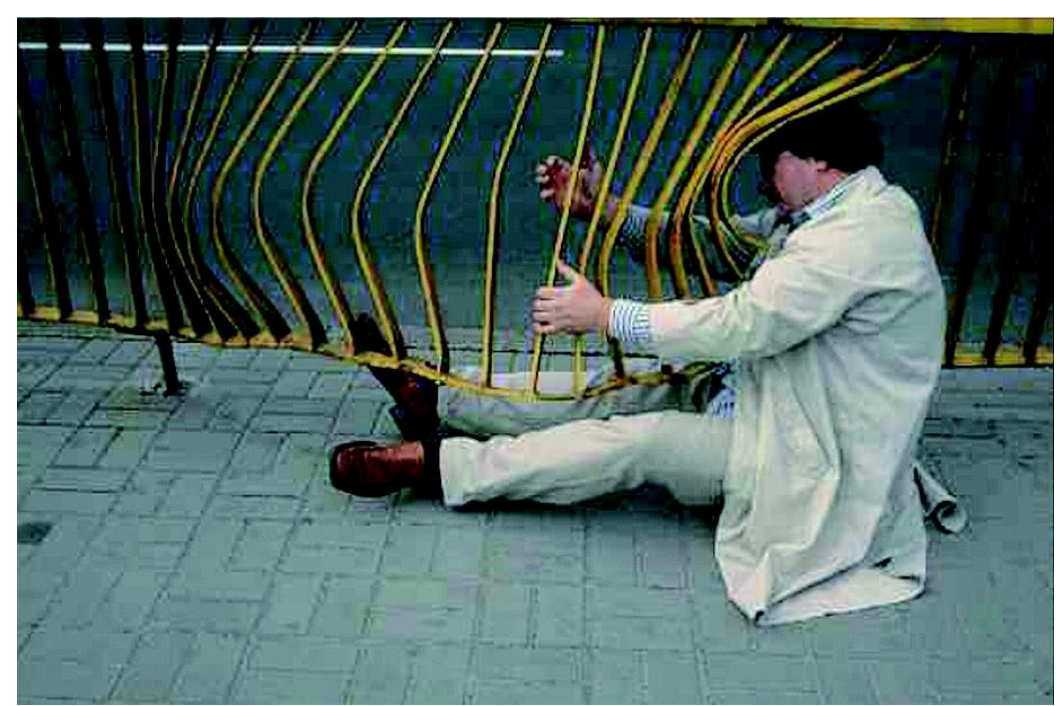

Figura 2. Cezary Bodzianowski. Convex Meniscus, 2008

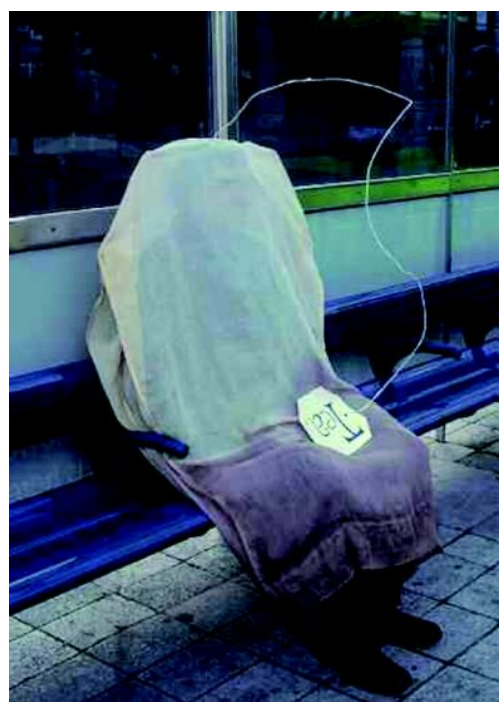

Figura 3. Tea Bag, 2011

En cada uno de sus teatros personales y eventos, Bodzianowski transforma la obra de arte y la experiencia artística en un espacio de ilógica y contrariedad. En su grotesco imaginario los gestos atentos y miradas furtivas del Prometeo del despropósito y la burla, avasallan vallas publicitarias urbanas [fig. 1], o tocan música callejera [fig. 2]. Ya sea como bolsita de té gigante [fig. 3] o llevando un

\footnotetext{
4 En referencia a La Comunidad que Viene (1996) del filósofo italiano Giorgio Agamben, cuyos personajes se sumergen en un mundo postmetafísico y el ser deviene «impropiedad» y «vida sin forma».
} 
carrito de la compra de paseo (Passer, 2002), Bodzianowski nos sumerge en el despropósito del día a día. Sus preparaciones, esperas y rupturas invalidan el exceso y se detienen en el detalle y lo concreto.

En términos objetuales, su imaginario es igualmente contrario y absurdo. Su atrezo se satura de cosas y re-cosas, superposiciones (in)coherentes y tácticas cómplices de lo performativo. ¿Y cual es el resultado? El modelado de un dibujo que transforma, desdice y descontextualiza lo objetual. Así, el manillar de una puerta se transforma en pistola (Boa-gun, 2008), la comodidad de un sillón en la tecnología de un monitor invertido (Segnatura, 2008), y las patas de una silla bocabajo en una tarta de cumpleaños (Birthday, 2009). Entre los originales y copias de sus formas y performances burlescas, tan pronto vemos homenajes al biciclo de Duchamp, como a la absurdidad de los Incoherentes e Hidrópatas ${ }^{5}$, o la máscara del actor minstrel de la comedia primitiva. Así, su imaginería muestra una rueda de bicicleta solitaria atada a la barandilla de unas escaleras (Giro d'Italia, 2007) y, evocando el famoso lienzo de Paul Bilhaud6, entre sus teatros personales descubrimos a Bodzianowski desnudo teñido de negro, en una cama negra, escuchando música negra en una radio negra sobre un fondo negro (Black Man Listening to Black Music on a Black Background, 1996). Como en la mundología de Los Incoherentes, la síntesis y destreza de Bodzianowski favorece «la abolición de la lógica, el sentido común, y el advenimiento de lo irrisorio" (Charpin, 1990, p. 86).

Fiel a esa brevedad, al personaje clown-acróbata y al ingrediente slap-stick que nos exponía el personaje circense y la comedia cinemática primitiva, sus disparates pueden ocurrir en la intimidad de un cuarto de baño (Rainbow Bathroom Lodz, 1995), o desafiar la enormidad de la escultura a lo Claes Oldenburg paseándose por la calle con un cucurucho de helado estampado en la frente (Numbers and dates, 2007). Sus acrobacias clownescas se esconden de cabeza en el hueco de unas escaleras (Tao perteneciente a Julietta Project, 2007), pilotan un avión en medio de la galería (The planned Landing, 2006), o juegan a los aros con pivotes del paisaje urbano (Serso, 2008). Y entre sus máscaras, descubrimos largas melenas encrespadas (Afro, 1999; Frizo, 2012), collarines isabelinos para mascotas y trajes de marinero (4 x Paris, 2004), o neumáticos y figuras a lo Michelín (Credimi, 2010). Sus teatros personales de los eventos, son espacios dramáticos risibles, estructuras inestables, monumentos a los monumentos caídos del habituado [fig. 4].

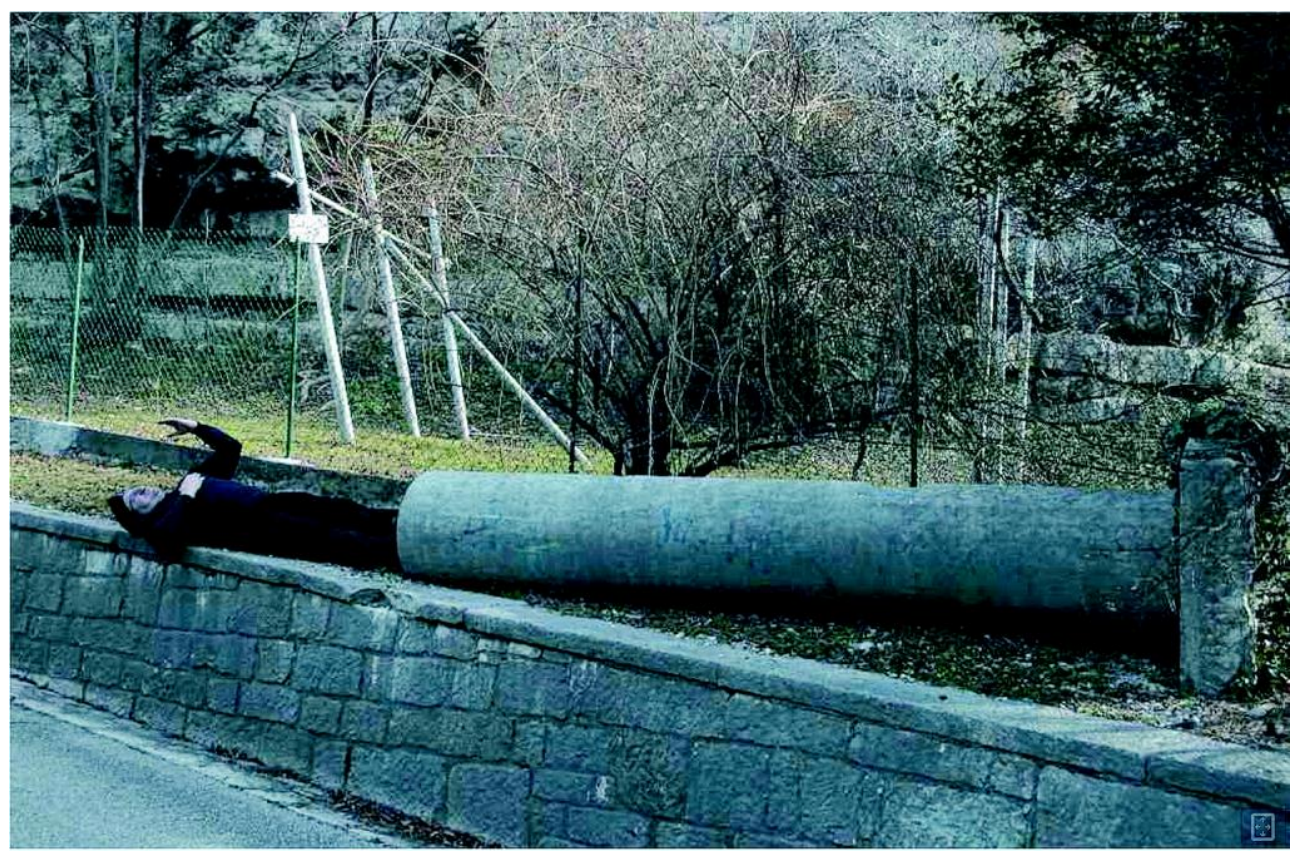

Figura 4. Cezary Bodzianowski. Auto-da-fé, 2007

\footnotetext{
5 Considerados el eslabón perdido del arte contemporáneo, Les Incohérents surgen en el París de finales del siglo XIX y principios del XX para confrontar el formalismo academicista de la época. Pertenecientes al ámbito de la literatura, la poesía, la ilustración, el arte; la incoherencia, explica Charpin, sería para el arte serio lo que el cancán francés para el ballet clásico. Es decir, «una especie de pariente lejano, con expresión propia y ambiciones desorbitadas» (1990, p.63).

6 En referencia a Combat des nègres dans une cave, pendant la nuit (1882). Lienzo monocromo en negromisma línea que sugiere los monocromos allaisianos. Se trata, en palabras de Charpin, de, increíbles «profecías de arte moderno» (Charpin, 1990, p. 75). Estos lienzos se convierten en «reflexiones irónicas» del impresionismo, la innovación y lo burlesco en el Montmartre de finales del siglo XIX y principios del XX.
} 
Con alma de payaso y comprometido con los escenarios del desatino y personaje cotidiano, la preparación, espera y ruptura del gag es definitivamente la fórmula. En el fondo del gag sennettiano, escribe Arnheim en 1936, hay tal vez "un elemento fundamental de vida que puede estar vinculado a oscuras sensaciones ancestrales, derivados de un duro y lejanísimo pasado de salvaje lucha por la existencia», y cuyos personajes se ven enfrentados, como el hombre primitivo, a sus semejantes, al entorno, "a los poderes adversos del destino" (cit. por Paolella, 1967, p. 185). De la misma manera, Bodzianowski, su destreza clownesca y poderes adversos transforman el olimpo de la trivialidad en algo absurdamente extraordinario.

\section{CONCLUSIONES}

De naturaleza improductiva y contraria, la capacidad del gag para transformar los significados y expectativas de lo que está ocurriendo, lo convierten en un prototipo de exceso y síntesis perfecto. Sus constantes son la paradoja y la sorpresa, los dobles sentidos, la farsa y el enredo. El gag como estrategia discursiva nos sumerge en la riqueza de la mente del principiante. Una mente vacía de contenidos, expectativas y lógicas. Una mente que, en palabras de Roshi, está «dispuesta a aceptar, dudar, abrirse a todas las posibilidades» (Cit. por Zukav, 2009, p. 118). Con sus gags y payasadas, el discurso contemporáneo nos invita a repensar la vorágine cotidiana, a meditar la pantomima social, a recuperar los sentidos, a desconfiar de la lógica, a dialogar desde la risa y el despropósito. A distinguir, de verdad, lo que miramos. A cuestionar lo que vemos y no vemos. A reírnos más y pensar menos, sin dejar por eso de comprometernos con la travesura contextual. Más bien todo lo contrario.

\section{ÍNDICE DE ILUSTRACIONES}

Fig. 1 Cezary Bodzianowski. Onto, 2009. Performance, Łódź urban space. Photo: Monika Chojnicka. Courtesy Foksal Gallery Foundation, Warsaw, Galleria Zero, Milan and artist. Catalog "This Place is Called the Hole" (2012). Edited by Herausgegeben von Jaroslaw Suchan pp.174-175.

Fig. 2 Cezary Bodzianowski. Convex Meniscus, 2008. Łódź urban space. Catalog “This Place is Called the Hole" (2012). Edited by Herausgegeben von Jaroslaw Suchan p.134.

Fig. 3 Cezary Bodzianowski. Tea Bag, 2011. Bristol private apartment and urban space. Catalog "This Place is Called the Hole" (2012). Edited by Herausgegeben von Jaroslaw Suchan p.201.

Fig. 4 Cezary Bodzianowski. Auto-da-fé, 2007. Trento. Ruins in the suburbs. Catalog "This Place is Called the Hole" (2012). Edited by Herausgegeben von Jaroslaw Suchan pp.96-97.

\section{FUENTES REFERENCIALES}

Agamben, G. (1996). La comunidad que viene (10 Edición, 1990). Valencia, España: Pre-Textos.

Arpa, A., Chiti, R., Pantieri, J., Popeschich, P., Verdone, M., y Zocaro, E. (1992). Cinema \& Circo in Italia. Roma, Italia: Edizioni del C.E.C.S

Bowser, E. (1988). Subverting the Conventions: Slapstick as Genre. En E. Bowser (Ed.), The Slapstick Symposium. The Museum of Modern Art New York 41st FIAF Congress (pp. 13-17). Nueva York: Federation Internationale Des Archives du Film.

Carroll, N. (1991). Notes of the Sight Gag. En A. S. Horton (Ed.), Comedy / Cinema / Theory (págs. 25-42). Berkely/Los Angeles, California, Estados Unidos: University of California Press.

Charpin, C. (1990). Les Arts Incohérents (1882-1893). París, Francia: Syros Alternatives.

Cremonini, G. (1977). Il comico e l'altro. Il comico nel cinema americano. Bologna, Italia: Cappelli Editore.

Dale, A. (2000). Comedy is a man in trouble. Minneapolis, MN, Estados Unidos: University of Minnesota press.

Gorządek, E. (13 de Noviembre de 2015). Life and work: Cezary Bodzianowski. Recuperado el 29 de Diciembre de 2015, de Culture PI: http://culture.pl/en/artist/cezary-bodzianowski 
Kràl, P. (2007). Le Burlesque ou la morale de la tarte à la crème. París, Francia: Éditions Ramsay.

Leydi, R., \& Bragaglia, A. G. (1959). La Piazza: spettacoli popolari italiani. Milán, Italia: Milano collana del “Gallo Grande”.

Mars, F. (1964). Le Gag. París, Francia: Éditions du Cerf.

Martín Peña, F. (1991). Gag: La comedia en el cine, 1895-1930 (Vol. 1991). Madrid, España: Catriel.

Moscariello, A. (2009). Gag. Guida alla comicità slapstick. Roma, Italia: Dino Audino Editore.

Paolella, R. (1967). Historia del cine mudo. Buenos Aires, Argentina: Editorial Universitaria de Buenos Aires.

Propaganda. (s.f.). Lodz Kaliska / Biography / Works. Recuperado el 26 de Enero de 2016, de Galeria Propaganda: http://galeriapropaganda.com/artists/lodz-kaliska/

Piercarlo, F. (1979). Guida al cinema comico. Milán, Italia: Editrice Gammalibri Milano.

Verwoert, J. (2007). O Lucky Man! Frieze (110), 238-243.

Vittori, M. V. (1990). Il clown futurista. Storie di circo, avanguardia e café-chantant. Roma, Italia: Bulzoni Editore 